Atmos. Chem. Phys., 10, 11277-11294, 2010

www.atmos-chem-phys.net/10/11277/2010/

doi:10.5194/acp-10-11277-2010

(C) Author(s) 2010. CC Attribution 3.0 License.

\title{
Multi sensor reanalysis of total ozone
}

\author{
R. J. van der A, M. A. F. Allaart, and H. J. Eskes \\ KNMI, P.O. Box 201, 3730 AE De Bilt, The Netherlands
}

Received: 23 February 2010 - Published in Atmos. Chem. Phys. Discuss.: 28 April 2010

Revised: 12 August 2010 - Accepted: 16 November 2010 - Published: 30 November 2010

\begin{abstract}
A single coherent total ozone dataset, called the Multi Sensor Reanalysis (MSR), has been created from all available ozone column data measured by polar orbiting satellites in the near-ultraviolet Huggins band in the last thirty years. Fourteen total ozone satellite retrieval datasets from the instruments TOMS (on the satellites Nimbus-7 and Earth Probe), SBUV (Nimbus-7, NOAA-9, NOAA-11 and NOAA-16), GOME (ERS-2), SCIAMACHY (Envisat), OMI (EOS-Aura), and GOME-2 (Metop-A) have been used in the MSR. As first step a bias correction scheme is applied to all satellite observations, based on independent groundbased total ozone data from the World Ozone and Ultraviolet Data Center. The correction is a function of solar zenith angle, viewing angle, time (trend), and effective ozone temperature. As second step data assimilation was applied to create a global dataset of total ozone analyses. The data assimilation method is a sub-optimal implementation of the Kalman filter technique, and is based on a chemical transport model driven by ECMWF meteorological fields. The chemical transport model provides a detailed description of (stratospheric) transport and uses parameterisations for gas-phase and ozone hole chemistry. The MSR dataset results from a 30-year data assimilation run with the 14 corrected satellite datasets as input, and is available on a grid of $1 \times 11 / 2^{\circ}$ with a sample frequency of $6 \mathrm{~h}$ for the complete time period (1978-2008). The Observation-minus-Analysis (OmA) statistics show that the bias of the MSR analyses is less than $1 \%$ with an RMS standard deviation of about $2 \%$ as compared to the corrected satellite observations used.
\end{abstract}

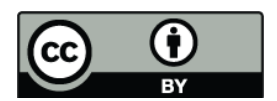

Correspondence to: R. J. van der A (avander@knmi.nl)

\section{Introduction}

Although ozone observations from space are available for 1971 and 1972 with the BUV instrument on Nimbus-4 (Stolarski et al., 1997), regular and continuous ozone monitoring from space in the UV-VIS spectral range is performed since 1978 with the TOMS and SBUV instruments on the satellite Nimbus-7 (Bhartia et al., 2002; Miller et al., 2002). These observations were continued with the TOMS instruments on Meteor 3, Earth Probe, and ADEOS until the year 2003, when the measurements started to be seriously affected by instrument degradation. This TOMS time series was interrupted from May 1993 until July 1996 when TOMSEP was launched. However, this gap was filled by continuous SBUV observations on various NOAA satellite missions. The gap was also partly filled with GOME ozone observations since July 1995 aboard ERS-2 (Burrows et al., 1999), the first European satellite instrument measuring total ozone from the UV-VIS. Although global coverage was no longer possible due to an instrumental problem in 2003, the GOME instrument is still measuring with reduced coverage. Follow-up European satellite instruments are SCIAMACHY (Bovensmann et al., 1999) launched in 2002 on the Envisat platform of European Space Agency (ESA) and OMI (Levelt et al., 2006), a Dutch-Finnish instrument on the EOSAURA platform of National Aeronautics and Space Administration (NASA), launched in 2004. The UV-VIS spectrometer GOME-2 (Callies et al., 2000) was launched in 2006 on the first of a series of three operational EUMETSAT Metop missions, which allows continuous monitoring of the ozone layer until about 2020.

Complementary to space observations are routine ozone column observations made at surface sites by Brewer, Dobson, and Filter instruments (e.g. Fioletov et al., 2008). Apart from their direct use in ozone monitoring (e.g. Staehelin et al., 2001), these observations have been a crucial source of information to test or validate satellite retrievals.

Published by Copernicus Publications on behalf of the European Geosciences Union. 
This study covers a period of more than 30 years of total ozone measurements from space using several UV-VIS satellite instruments. These datasets covering a long time period are important for monitoring stratospheric ozone, trend analyses (e.g. Stolarski et al., 1991; Fioletov et al., 2002, Brunner et al., 2006a; Stolarski et al., 2006b; WMO, 2007; Mäder et al., 2007; Harris et al., 2008) and calculating the UV radiation at the Earth's surface (Lindfors et al., 2009; Krcyścin, 2008). However, the measurements used are originating from different instruments, different retrieval algorithms and are suffering from instrument problems like radiation damage. The data usually shows offsets in overlapping time periods and differ from ground observations. A consistent longterm ozone dataset is important for quantifying ozone depletion and detecting first signs of recovery (e.g. Reinsel et al., 2005), following actions to reduce ozone-depleting substances as regulated by the Montreal Protocol and its amendments. In 1996, McPeters and Labow published a 14-year ozone dataset based on TOMS measurements and consistent with 30 Dobson and Brewer stations. Bodeker et al. (2001) constructed a 20 year ozone time series based on 5 homogenized satellite datasets using ground data as reference, which was later updated using data assimilation (Bodeker et al., 2005) and used to derive the vertical ozone distribution using data assimilation (Brunner et al., 2006b). Recently, Stolarski et al. (2006a) have created a dataset from 1978-2006 by combining TOMS and SBUV data. An overview of ozone trend studies before 2006 is provided in the WMO assessment of 2006 (WMO, 2007; and references therein).

The assimilation of ozone measurements has received considerable attention in the past 12 years. With the extension to the stratosphere, numerical weather prediction models have also included ozone as explicit model variable (Derber and $\mathrm{Wu}, 1998$ ). The 40-year reanalysis of the European Centre for Medium-Range Forecasts (ECMWF) includes the assimilation of ozone column satellite data (Dethof and Hólm, 2004) and is one of the first long-term ozone records available based on assimilated satellite data. This work highlighted some of the difficulties in generating a consistent data set based on a changing observation system and issues that may arise when only total column ozone data is available. Several other centres have set up near-real time and reanalysis capabilities to analyse ozone column data from satellites (e.g. Geer et al., 2006; Stajner et al., 2008; Eskes et al., 2003). Recently, Kiesewetter et al. (2010) presented a long-term stratospheric ozone data set from the assimilation of SBUV data.

In this paper we present a continuous and consistent ozone column dataset of 30 years, based on the assimilation of satellite observations. The data assimilation method (Eskes et al., 2003) is based on the Kalman filter technique that expects unbiased input data with a known Gaussian error distribution. In order to provide these unbiased input data, first a new retrieval (level 2) dataset has been created by correcting all satellite data for biases using ground data as a reference.
(Level 2 data is defined as "geolocated geophysical product"; in this paper it is the retrieved ozone column on the satellite footprint.) These datasets are corrected for biases as function of the solar zenith angle, viewing angle, time (trend), and effective ozone temperature, which are critical parameters for errors in the retrievals. Sometimes two level 2 data sets from the same instrument are available. However, these data sets from the same instrument can be seen as independent measurements since their errors are not more correlated than the errors within a single data set. In order not to show any preferences, both data sets have been used.

Fourteen total ozone satellite datasets have been identified and collected from the satellite instruments TOMS, SBUV, GOME, SCIAMACHY, OMI and GOME-2. In addition, all ground based total ozone observations have been collected from the World Ozone and Ultraviolet Data Center (WOUDC, 2009) archive, and a dataset with global effective ozone temperatures has been created. These datasets are described in Sect. 2. A reference dataset has been selected, and the corrections that need to be applied to the satellite datasets to bring them in line with the reference dataset have been computed. These corrections are described in Sect. 3 . An intermediate dataset, called the Multi Sensor Reanalysis (MSR) level 2 dataset, has been created. This dataset contains virtually all corrected satellite measurements for the thirty-year period. The data assimilation system (TM3DAM) has been modified slightly to make the best use of the data. This modification is described in Sect. 4. In Sect. 5 the final MSR level 4 data, created with the data assimilation system, is analyzed.

\section{Ozone observations}

\subsection{Satellite ozone measurements}

The fourteen satellite total ozone datasets used in this study are listed in Table 1. Each dataset is identified with an acronym: TOMS2a, TOMS2b, SBUV07, SBUV9a, SBUV9d, SBUV11, SBUV16, GDP, TOGOMI, SGP, TOSOMI, OMDOAO3, OMTO3, and GOME2. Details on the datasets are presented in Appendix A. Two other datasets have been used in this study, namely the WOUDC collection of ground based total ozone data (Sect. 2.2), and a dataset of ECMWF effective ozone temperatures (Sect. 2.5).

All the currently available satellite level 2 total ozone datasets have been used. However, this collection is not complete. Up to date level 2 data from the TOMS instruments on board the Meteor 3 and ADEOS satellites were not available. Gridded (level 3) data is available, but this data is not suitable for data assimilation. SBUV/2 data after 2003 was not available. However, because of the relatively small number of observations compared to the other instruments these data would have a minor impact on the analyses. 
Table 1. The satellite datasets used in this study. The columns show the name of the dataset, the satellite instrument on which it is based, the satellite, the period(s) used, the maximum distance allowed in an overpass, the number of ground instruments (WSI) and the total number of overpasses for this dataset.

\begin{tabular}{llllllrr}
\hline Name & Instrument & Satellite & From & To & Dist. & \#WSI & Overpasses \\
\hline TOMS2a & TOMS & Nimbus-7 & 1 Nov 1978 & 6 May 1993 & $0.75^{\circ}$ & 137 & 182464 \\
TOMS2b & TOMS & Earth probe & 25 Jul 1996 & 31 Dec 2002 & $0.75^{\circ}$ & 146 & 129839 \\
SBUV07 & SBUV & Nimbus-7 & 31 Oct 1978 & 21 Jun 1990 & $2.00^{\circ}$ & 112 & 24345 \\
SBUV9a & SBUV/2 & NOAA-9 & 2 Feb 1985 & 31 Dec 1989 & $2.00^{\circ}$ & 099 & 11705 \\
SBUV9d & SBUV/2 & NOAA-9 & 1 Jan 1992 & 19 Feb 1998 & $2.00^{\circ}$ & 135 & 22706 \\
SBUV11 & SBUV/2 & NOAA-11 & 1 Dec 1988 & 31 Mar 1995 & $2.00^{\circ}$ & 166 & 38874 \\
& & & 15 Jul 1997 & 27 Mar 2001 & & & \\
SBUV16 & SBUV/2 & NOAA-16 & 3 Oct 2000 & 31 Dec 2003 & $2.00^{\circ}$ & 131 & 16384 \\
GDP & GOME-1 & ERS-2 & 27 Jun 1995 & 31 Dec 2008 & $1.80^{\circ}$ & 156 & 108758 \\
TOGOMI & GOME-1 & ERS-2 & 1 Apr 1996 & 31 Dec 2008 & $1.80^{\circ}$ & 155 & 107276 \\
SGP & SCIAMACHY & Envisat & 2 Aug 2002 & 31 Dec 2008 & $0.90^{\circ}$ & 139 & 50017 \\
TOSOMI & SCIAMACHY & Envisat & 2 Aug 2002 & 31 Dec 2008 & $0.90^{\circ}$ & 139 & 47532 \\
OMDOAO3 & OMI & Aura & 1 Oct 2004 & 31 Dec 2008 & $0.90^{\circ}$ & 123 & 84089 \\
OMTO3 & OMI & Aura & 17 Aug 2004 & 31 Dec 2008 & $0.90^{\circ}$ & 125 & 83405 \\
GOME2 & GOME-2 & Metop-A & 4 Jan 2007 & 31 Dec 2008 & $0.45^{\circ}$ & 105 & 28538 \\
\hline
\end{tabular}

\subsection{Ground based data}

At many sites across the globe ground based instruments are employed to measure total ozone on a daily basis. This longterm dataset provides an excellent reference for the validation of satellite instruments. Extensive research in the performance of this network has been recently published by Fioletov et al. (2008). Their Table 3 shows the characteristics of the different components of the network. The WOUDC collects these ground-based observations, and makes them available for research. From this collection a WOUDC-StationInstrument (WSI) list has been defined. This list has an entry for each type of instrument for each ground station, where type of instrument refers to Dobson (113), Brewer MKII (40), Brewer MKIII (14), Brewer MKIV (39), Filter (62), and Other (7). The number between brackets is the total number of each instrument occurring in the WSI list. In total the WSI-list contains 275 instruments. A discussion of the differences between the various ground instruments is beyond the scope op this paper. Some information is available in Staehelin et al. (2003).

The daily average total ozone observations for each WSI, in the period 1978-2008, have been extracted. The time resolved observations have not been used, as these are available only for a limited number of stations. All ground instruments distinguish between DirectSun and ZenithSky observations. DirectSun data is deemed superior, as the retrieval is relatively straightforward, not requiring the calculation (explicitly or implicitly) of light scattered in the atmosphere. For some of the Brewer sites the ZenithSky data appears not to have been calibrated properly (Fioletov et al., 2008). Therefore, only DirectSun data have been used in this study.
Data that seems odd (for example Direct Sun observations during the polar night) have been rejected. Furthermore a "blacklist" has been created that indicates for each year and for each WSI if the data is suspect. Suspect data has been identified by comparison with various satellite datasets. If sudden jumps, strong trends or very large offsets are identified, the WSI is blacklisted. This subjective blacklist is quite similar to the one used by Bodeker et al. (2001). In total 5\% of the ground data has been blacklisted.

\subsection{Satellite overpass datasets}

For each satellite product an "overpass" dataset has been created for each entry in the WSI list. As only total ozone values derived from measurements of scattered sunlight by satellites in a polar orbit have been used, these observations are naturally divided in sections of about $45 \mathrm{~min}$ (an "orbit"), when the satellite is on the sunlit side of the Earth. The overpass value for an orbit is the satellite observation that has the centre of its footprint closest to the ground station. For each satellite product a maximum allowed distance between the centre of the ground pixel and the ground station was defined. This number is typically $50-200 \mathrm{~km}$ depending on the ground pixel size, see details in Table 1. A local date/time has been defined as the satellite UTC date/time of the satellite observation plus a correction based on the longitude of the ground station. In this way, the satellite date corresponds directly to the date reported in the ground station data. Apart from the local date/time and the total ozone value, auxiliary data is also recorded, like the measurement error, the Solar Zenith Angle (SZA), the Viewing Zenith Angle (VZA), cloud properties and the distance from the centre 
of the footprint to the ground station. There can be up to fifteen overpass values per day. From these only one is selected and used. This is the one with the smallest reported observation error or the one closest to the ground station if the observation error is not available.

\subsection{Seasonal behaviour}

With the WOUDC observations and the satellite overpass data prepared as discussed above, it is now possible to compare these measurements for each WSI. As an example Fig. 1 shows the monthly averaged anomalies (defined as satellite measurement minus ground measurement) over the Netherlands as a function of time. It is clear that either the ground station data and/or the satellite data contain a seasonally dependent error. A study of all satellite products for this station (Brewer MKIII, De Bilt) shows that a seasonal effect like this is fairly typical, but the amplitude and phase differs from one satellite product to the other. The seasonal cycles of the anomaly of the two satellite products shown here are even in anti-phase. This suggests that at least some of the satellite products have a seasonal offset. A study of all European ground stations versus one satellite product shows that for a large majority of ground stations the results are similar. One cannot conclude from this that the data from the ground stations is essentially correct, as the ground stations are normally calibrated by inter-comparison. Further inspection shows, however, that the seasonal offsets between ground stations and satellite products are clearly different in other regions of the world. This suggests that the offset could depend on latitude, SZA and/or effective ozone temperature, rather than time. It is not uncommon to find seasonal anomalies when satellite ozone values are compared to other ozone products, see for example Lerot et al. (2009), Bodeker et al. (2001) and Eskes et al. (2005).

\subsection{Effective ozone temperature}

The ozone absorption cross-section needed as input for the retrieval algorithms depends on temperature. Ignoring this effect will lead to a time and certainly seasonal dependent offset in the total ozone data. This is true for both ground stations and satellite products. A dataset of effective ozone temperatures has been created to study the temperature dependence of the total ozone data. The effective ozone temperature is defined as the integral over altitude of the ozone profile-weighted temperature. This dataset was calculated from ECMWF (6 hourly) temperature profiles, and the (seasonal dependent) Fortuin and Kelder ozone climatology (Fortuin and Kelder, 1998). For the years 1978-1999 the ECMWF ERA40 reanalyses, and for the years 2000-2008, the ECMWF operational analyses have been used. For each ground station a dataset of daily values was created with the effective ozone temperatures interpolated to local noon.

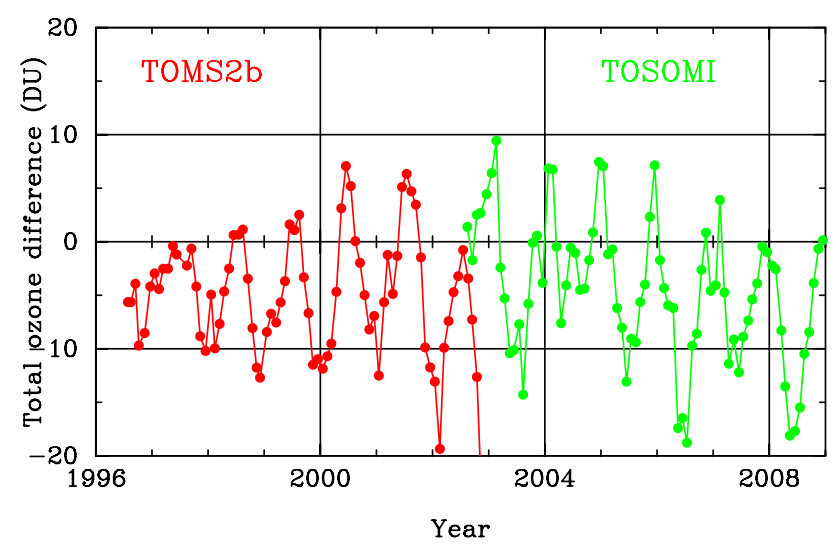

Fig. 1. Monthly averaged anomalies for the overpass data at the ground station De Bilt $\left(5.18^{\circ} \mathrm{E}, 52.1^{\circ} \mathrm{N}\right)$ in the Netherlands. The anomalies for TOMS2b (red) correlate with effective ozone temperature, while the anomalies for TOSOMI (green) correlate with solar zenith angle.

\subsection{The reference dataset}

Creating a consistent and coherent assimilated dataset requires that systematic offsets between the satellite retrieval products are small. A practical way to accomplish this is to choose a reference dataset, and subsequently correct the systematic effects in the other datasets, to bring them in line with the reference dataset. As the true total ozone values are not known, the choice of a reference dataset is somewhat arbitrary. The ground measurements are a logical choice, because these are present for the full 30-year period. The DirectSun measurements from the ground stations are a prime candidate. However, the measurement method used by the Brewer instruments is very sensitive to small details in the ozone absorption cross section, and the various available laboratory measurements of the ozone absorption coefficients give totally different dependencies of the retrieved total ozone values as function of the effective ozone temperature (Redondas and Cede, 2006). Kerr (2002) has developed a new methodology for deriving total ozone and effective ozone temperature values from the observations made with a Brewer instrument. He concludes that the effective ozone temperature has little effect on the amount of ozone derived with the standard algorithm. So in this study the data from the Brewer network has been adopted as a primary reference.

There are 21 stations in the WOUDC database where a Dobson instrument is co-located with a Brewer instrument. This, together with the effective ozone temperature $T_{\text {eff }}$ (in degrees Celsius) for this location, allows calculation of the Dobson versus the Brewer temperature dependence. This calculation confirms the results of Kerr (2002). A temperature correction based on Kerr (2002) of the total ozone amount $X$ 
$X_{\text {corr }}=X_{\text {dobson }} \cdot\left(1-0.0013 \cdot\left(T_{\text {eff }}+46.3\right)\right)$

has been applied to all Dobson total ozone data.

The WOUDC database contains data from 62 Filter instruments. These instruments are typically located in former USSR countries. Insufficient Filter instruments are colocated with either Brewer or Dobson instruments to make a statistical analysis of the behaviour of this instrument. A statistical analysis of ground station minus satellite total ozone values for these instruments has shown that the random measurement errors (or "noise") of these instruments are significantly higher than those of the Brewer or Dobson Instruments. Therefore the Filter instruments have not been used in the reference dataset.

In summary, the reference dataset consists of all WOUDC instruments, excluding the Filter instruments, and the Dobson data has been corrected for effective ozone temperature.

\section{Corrections for the satellite datasets}

\subsection{Introduction}

In this section the procedure to calculate corrections to the various satellite total ozone datasets will be presented. Ozone differences are defined as: "ground based observations minus satellite observations". The corrections are obtained by fitting these differences as a function of "predictors" using a simple multi-dimensional least squares fitting system. The predictors are the auxiliary information available in the satellite product, and the effective ozone temperature (Sect. 2.5). The fitting procedure uses all overpasses shown in Table 1 to calculate the corrections for the satellite dataset in question.

\subsection{Choice of the predictors}

The ozone differences (satellite minus ground observation) show a clear seasonal cycle, which is illustrated in Fig. 2a, where the satellite observations are compared with ground observations. This led to the choice of SZA and effective ozone temperature as predictors, as these imply a clear seasonal component. Note that it has been checked that the SZA and effective ozone temperature are not interchangeable as predictor. Some of the satellite products show a clear trend in time, so the number of years since 2000 is another obvious choice. The scan- or view angle is also used as predictor. Although most satellite datasets contain this quantity, it is defined in various ways. To overcome these differences, the Viewing Zenith Angle (VZA) has been defined as the angle in the scanning direction (or increasing row number for OMI), with the largest negative value in the beginning of the scan, zero at nadir, and the largest positive angle at the end of the scan. It was found that some of the data product anomalies have a non linear dependence on VZA. In these cases an offset per pixel along the "scan" was used.

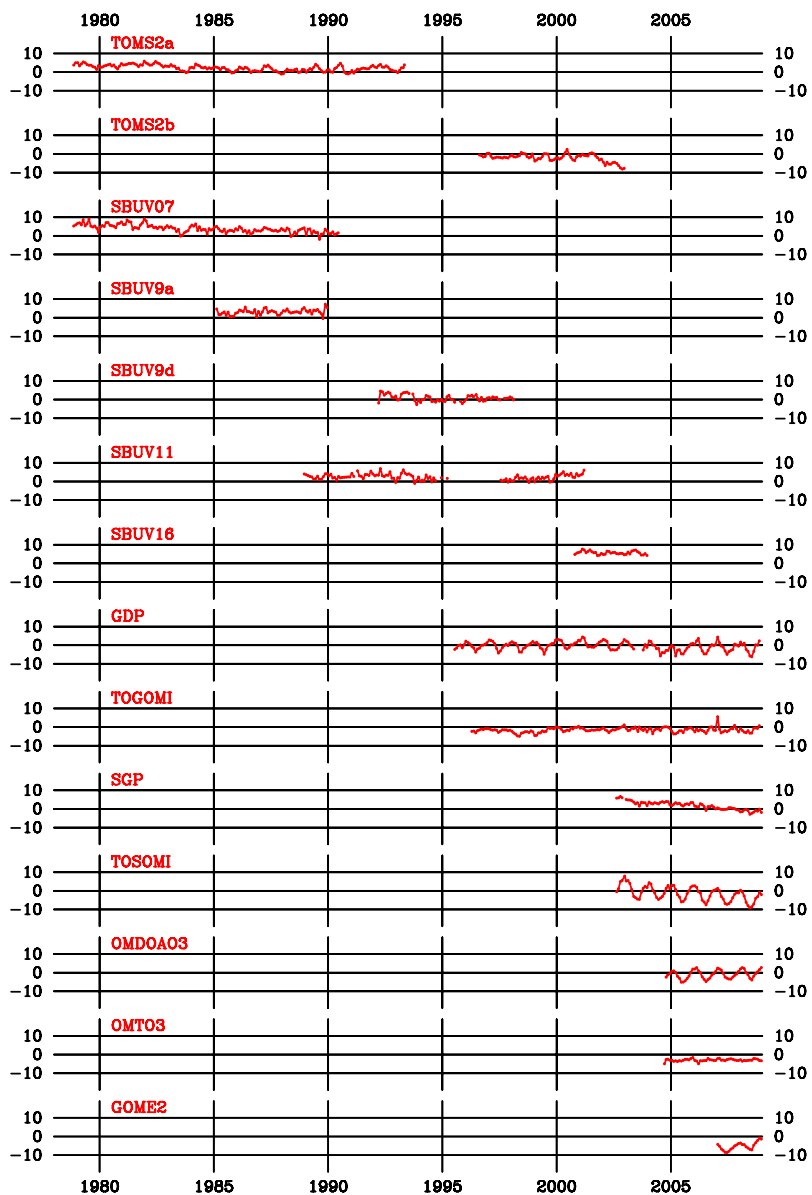

Fig. 2a. Monthly averaged and globally averaged difference of the satellite ozone observation minus the ground observation in units of DU, for all satellite data sets used as function of time.

Bodeker et al. (2001) analyzed ozone differences in terms of time and latitude only. They have used 22 predictors for their fit. The approach in this paper is different, because SZA and effective ozone temperature appeared to be better predictors. Furthermore, these are critical parameters in the retrieval schemes and therefore constitute a more satisfying choice to estimate systematic biases. When these predictors are used the need for an explicit seasonal or latitudinal dependence almost disappears. A WSI dependent offset was allowed when the regression coefficients were computed. This has been done to reduce the effect (e.g. spurious trends) of "appearing" and "disappearing" ground stations during the lifetime of the satellite instrument from the results.

A basic assumption is that all the corrections are additive to the total ozone amount: $X_{\mathrm{corr}}=X_{\mathrm{sat}}+\sum_{i} C_{i} P_{i}$, where $C_{i}$ is the correction for predictor $P_{i}$. Hence the current formulation does not allow for a multiplicative correction like $X_{\text {corr }}=\alpha X_{\text {sat }}$ with $\alpha$ close to 1 . 


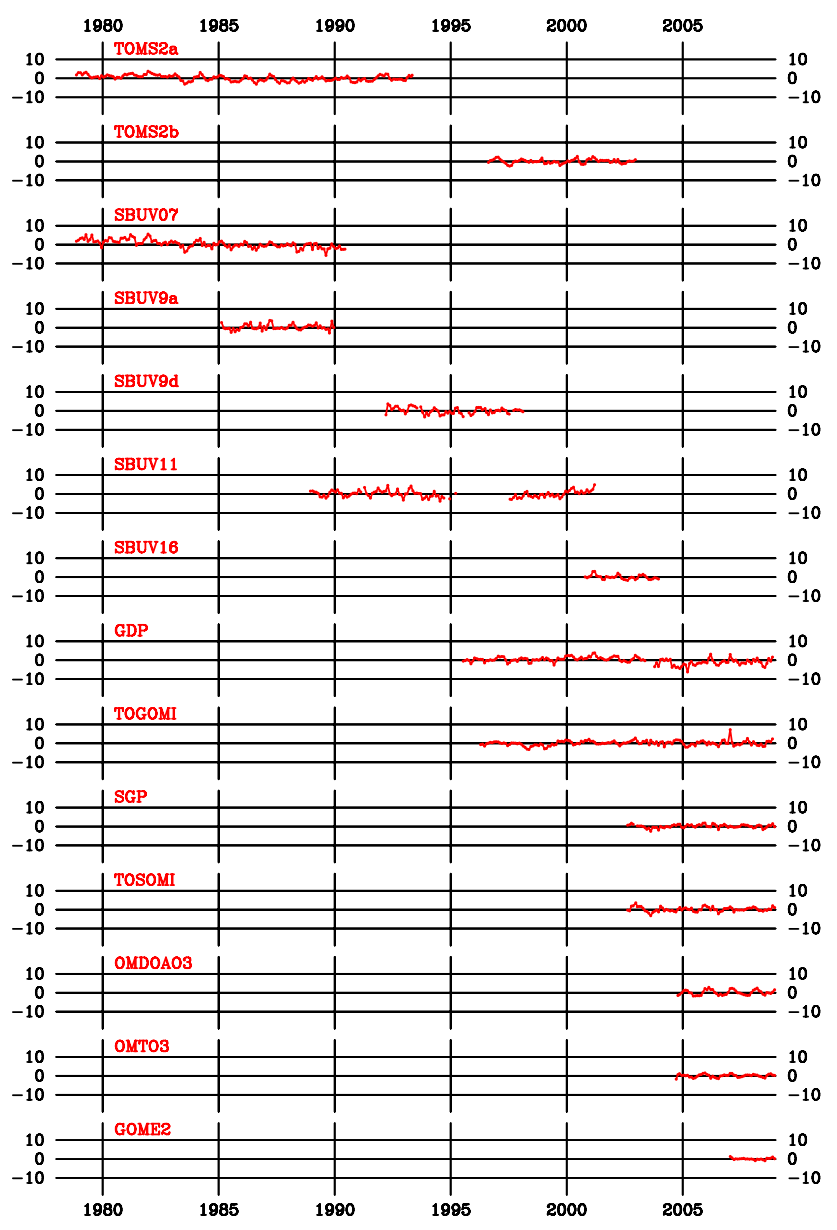

Fig. 2b. Monthly averaged and globally averaged difference of the corrected (as described in Sect. 3.5) satellite ozone observation minus the ground observation in units of DU, for all satellite data sets used as function of time.

\subsection{Calculation of the corrections}

The regression coefficients for the four predictors and for all fourteen satellite datasets are listed in Table 2. As indicated in Sect. 3.2, an additional offset per WSI (one offset for each type of instrument at each ground station) was used, which are not shown in Table 2. Thus, the total number of predictors is in the order of 150 per satellite dataset. Note that the SBUV instruments perform only nadir measurements and the VZA dependence is therefore absent.

Clearly visible are the trends in the SCIAMACHY and GOME2 datasets. For four datasets (TOMS2b, GDP, TOGOMI, and GOME-2) the VZA dependence is not linear, so the value given here is only indicative. The same is true for the SZA value in the OMDOAO3 dataset. The temperature dependence varies from -0.44 to $+0.34 \mathrm{DU} / \mathrm{K}$. The two OMI products show opposite temperature dependency, e.g. negative for OMTO3 and positive for OMDOAO3.
For the purpose of data assimilation it is relevant to reduce offsets, trends and long-term variations in the satellite data, so that the data can be used as input to the assimilation scheme without biases and with known standard deviations. The satellite data set corrections are based on a few relevant regression coefficients fitted for the overpass time series of all stations together. By fitting all data together regional biases that may be caused by offsets of individual ground instruments are avoided. From here on the offset per WSI reported above will no longer be used. The relevant regression coefficients, i.e. those that reduce the RMS (Root Mean Square) between satellite and ground observations significantly, have been calculated and are shown in Table 3 . Note that in this paper all RMS values have been calculated with the mean value of the data as reference, thus a correction of the overall offset will not improve the RMS. The total RMS is in fact dominated by the error of the ground observations, the representativity errors and the variance of the observations which are larger than the bias terms. A small decrease of the RMS is expected as a result of the correction.

The details of the resulting corrections are detailed in Appendix A. The TOMS2b dataset has been corrected for a trend for the last two years only. The datasets that show a non-linear dependence on VZA have been corrected on a "per pixel" basis. There could however be an issue with correcting on a "per pixel" basis. If the satellite is in an orbit with a short repeat cycle, each pixel gets calibrated with a unique subset of ground stations. This could lead to a spurious offset per pixel. Selecting an orbit with a long repeat cycle should avoid this issue in future missions. The OMDOAO3 dataset has been corrected for a quadratic SZA dependence (indicated with "nonlin" in Table 3).

Finally a single offset per satellite dataset was computed. In this calculation the number of predictors was quite low, about 2-4 per satellite instrument. For example for the SBUV07 datasets only two predictors were used: the effective ozone temperature and an offset. Table 3 lists the RMS value with no corrections (offset only) as RMS3, and RMS4 shows the value after the corrections have been applied. RMS3 and RMS4 are higher than respectively RMS 1 and RMS 2 since the RMS in Table 2 is calculated by fitting an offset for each station and the RMS in Table 3 is calculated using a single offset for all stations. Details of all the corrections in Table 3 are in the appendix. From the Table it is clear that the OMTO3 dataset is the best satellite dataset available, in the sense that it corresponds best with the (ground based) reference dataset. GOME2 shows promise, but is currently hampered by a large spurious trend. It is remarkable that all "American" data (TOMS, SBUV, OMTO3) require a negative temperature correction, while most "European" data (GOME, SCIAMACHY, GOME2) do not need a temperature correction. The OMDOAO3 dataset is the only one showing a positive correction. As there has been a trend in stratospheric temperatures in the 30-year period (Randel et al., 2009), it is conceivable that this trend shows up as a 
Table 2. Regression coefficients (expressed as corrections) for the various ozone datasets. The columns are (1) Name; (2) RMS original data; (3) Trend correction; (4) Viewing zenith angle correction, (5) Solar zenith angle correction; (6) Effective ozone temperature correction; (7) RMS after application of these corrections.

\begin{tabular}{|c|c|c|c|c|c|c|}
\hline Name & $\begin{array}{r}\text { RMS1 } \\
\text { (DU) }\end{array}$ & $\begin{array}{r}\text { Trend } \\
\text { (DU/year) }\end{array}$ & $\begin{array}{r}\text { VZA } \\
\text { (DU/deg.) }\end{array}$ & $\begin{array}{r}\text { SZA } \\
\text { (DU/deg.) }\end{array}$ & $\begin{array}{r}T_{\text {eff }} \\
\left(\mathrm{DU} / \mathrm{C}^{\circ}\right)\end{array}$ & $\begin{array}{r}\text { RMS2 } \\
\text { (DU) }\end{array}$ \\
\hline TOMS2a & 8.97 & 0.05 & 0.01 & 0.01 & -0.43 & 8.75 \\
\hline TOMS2b & 8.98 & 0.51 & 0.02 & 0.02 & -0.43 & 8.61 \\
\hline SBUV07 & 10.01 & 0.29 & N/A & -0.03 & -0.19 & 9.95 \\
\hline SBUV9a & 10.43 & -0.95 & N/A & 0.11 & -0.16 & 10.28 \\
\hline SBUV9d & 9.68 & -0.03 & N/A & -0.04 & -0.26 & 9.63 \\
\hline SBUV11 & 9.89 & 0.05 & N/A & 0.06 & -0.17 & 9.79 \\
\hline SBUV16 & 9.61 & 0.31 & N/A & 0.01 & -0.44 & 9.33 \\
\hline GDP & 8.89 & 0.00 & 0.05 & -0.11 & 0.03 & 8.72 \\
\hline TOGOMI & 8.08 & -0.17 & 0.07 & 0.01 & -0.01 & 7.94 \\
\hline SGP & 9.11 & 1.09 & -0.01 & -0.04 & -0.07 & 8.92 \\
\hline TOSOMI & 8.66 & 1.04 & 0.05 & -0.27 & 0.05 & 7.67 \\
\hline OMDOAO3 & 8.55 & -0.36 & -0.01 & -0.07 & 0.34 & 8.19 \\
\hline OMTO3 & 6.62 & 0.13 & -0.05 & -0.05 & -0.39 & 6.46 \\
\hline GOME2 & 7.21 & -2.19 & -0.03 & -0.19 & -0.10 & 6.60 \\
\hline (MSR-L2) & 8.77 & 0.00 & 0.00 & 0.02 & 0.03 & 8.76 \\
\hline
\end{tabular}

Table 3. Corrections that have been applied to the satellite datasets. The columns are: (1) Name; (2) RMS original data; (3) Trend correction; (4) View angle correction; (5) Solar angle correction; (6) Effective ozone temperature correction; (7) RMS after application of these corrections. Only one offset per satellite instrument is used here.

\begin{tabular}{lrlllrr}
\hline Name & $\begin{array}{r}\text { RMS3 } \\
(\mathrm{DU})\end{array}$ & $\begin{array}{l}\text { Trend } \\
(\mathrm{y} / \mathrm{n})\end{array}$ & $\begin{array}{l}\text { VZA } \\
(\mathrm{y} / \mathrm{n})\end{array}$ & $\begin{array}{l}\text { SZA } \\
(\mathrm{y} / \mathrm{n})\end{array}$ & $\begin{array}{r}\mathrm{T}_{\text {eff }} \\
\left(\mathrm{DU} / \mathrm{C}^{\circ}\right)\end{array}$ & $\begin{array}{r}\text { RMS4 } \\
(\mathrm{DU})\end{array}$ \\
\hline TOMS2a & 10.16 & no & no & no & -0.462 & 9.98 \\
TOMS2b & 9.84 & partial & pixel & no & -0.447 & 9.33 \\
SBUV07 & 11.12 & no & no & no & -0.153 & 11.09 \\
SBUV9a & 11.87 & no & no & no & -0.376 & 11.81 \\
SBUV9d & 10.66 & no & no & no & -0.196 & 10.63 \\
SBUV11 & 10.65 & no & no & no & -0.258 & 10.60 \\
SBUV16 & 10.43 & no & no & no & -0.467 & 10.22 \\
GDP & 9.60 & no & pixel & yes & no & 9.39 \\
TOGOMI & 8.95 & no & pixel & no & no & 8.84 \\
SGP & 9.99 & yes & yes & no & no & 9.80 \\
TOSOMI & 9.80 & yes & yes & yes & no & 8.98 \\
OMDOAO3 & 9.41 & yes & no & nonlin & +0.300 & 9.01 \\
OMTO3 & 7.60 & no & no & no & -0.282 & 7.45 \\
GOME2 & 8.30 & yes & pixel & yes & no & 7.71 \\
\hline
\end{tabular}

spurious trend in the ozone data, if the satellite products are not corrected for effective ozone temperature.

\subsection{Random errors}

The data assimilation procedure requires a noise estimate for each observation. Not all datasets, however, provide a measurement error, and it is unclear if the measurement errors of one product can be compared to those in other products.
It was decided to calculate one typical number for all observations in a specific dataset. To calculate this number it was necessary to have an estimation of the random noise in the ground-based data. The 22 stations where both Dobson and Brewer instruments are available make it possible to estimate the noise in the ground station data. The RMS of the Brewer-Dobson difference is 6.47 DU. Assuming that the noise in both ground instruments is similar, this implies the noise in a single instrument is 4.57 DU. (In Sect. 3.5 it 
will be shown that the noise in the Brewer and the Dobson datasets are indeed similar.) For all satellite datasets the RMS of the ozone anomalies is computed, allowing for an offset per WSI. These values are shown as "RMS1" (before corrections) and "RMS5" (after corrections) in Table 4. Assuming the errors of the ground and satellite dataset are uncorrelated, "RMS5" is the quadratic sum of the errors in the satellite data and those in the ground data. This makes it possible to estimate the random error in the satellite data, shown as "RMS6" in Table 4. These values are used in the data assimilation process.

Note that these errors will consist of two contributions, namely an instrument-related part and a representation error. The latter describes how well ozone in the satellite footprint represents ozone at the point location. The low RMS of the OMTO3 dataset is probably at least partly related to the small footprint and the therefore small representativity error.

\subsection{The MSR level 2 dataset}

Based on the calculated corrections the merged MSR level 2 dataset has been created. The original satellite datasets were read, filtered for bad data and corrected according to the formulas listed in Appendix A, and finally merged into a single time ordered dataset. Essential information in the MSR level 2 dataset is time, location, satellite product index and ozone. The satellite product index indicates from which satellite product the measurement originates. It is used by the data assimilation (see below) to infer an uncertainty in this measurement, based on "RMS6" in Table 4. Some additional information is added that is not used in the data assimilation, but is however available for statistical analysis of the results. The effect of the corrections is shown in Fig. 2, which shows the deviations between satellite data and ground observations without corrections for the satellite data in Fig. 2a and after correcting the satellite data in Fig. $2 b$. The trend, offset, and seasonal cycle in the satellite observations has been reduced to a negligible level in the MSR level 2 data set. These figures have also been made for zonally averaged deviations with similar results.

The MSR data can be used, and verified as any other satellite dataset. So it is possible to apply the regression system to this dataset. Ideally, the regressions coefficients would be zero. The results are shown at the bottom of Table 2. Since the MSR data consist of corrected satellite data, its RMS1 and RMS2 values are almost identical.

It is also possible to show the performance of the ground networks with this dataset. Table 5 gives the RMS noise of each of the networks versus the MSR level 2 dataset. The Brewer and Dobson datasets show a similar performance, while the Filter instruments show a larger RMS, in accordance with the results of Fioletov et al. (2008). The Brewer MKIII (which is still being produced) appears to be the superior instrument. Note again that this RMS also contains contributions from the satellite noise and representativity. How-
Table 4. Noise in the satellite dataset with respect to the ground network. RMS1 is before and RMS5 is after the corrections have been applied. RMS6 is the estimate of the noise in the satellite dataset itself.

\begin{tabular}{lrrr}
\hline Name & $\begin{array}{r}\text { RMS1 } \\
(\text { DU) }\end{array}$ & $\begin{array}{r}\text { RMS5 } \\
(\text { DU })\end{array}$ & $\begin{array}{r}\text { RMS6 } \\
(\text { DU) }\end{array}$ \\
\hline TOMS2a & 8.97 & 8.76 & 7.47 \\
TOMS2b & 8.98 & 8.45 & 7.10 \\
SBUV07 & 10.01 & 9.98 & 8.87 \\
SBUV9a & 10.43 & 10.34 & 9.27 \\
SBUV9d & 9.68 & 9.64 & 8.48 \\
SBUV11 & 9.89 & 9.82 & 8.69 \\
SBUV16 & 9.61 & 9.33 & 8.13 \\
GDP & 8.89 & 8.71 & 7.41 \\
TOGOMI & 8.08 & 7.96 & 6.51 \\
SGP & 9.11 & 8.92 & 7.66 \\
TOSOMI & 8.66 & 7.67 & 6.16 \\
OMDOAO3 & 8.55 & 8.17 & 6.77 \\
OMTO3 & 6.62 & 6.48 & 4.59 \\
GOME2 & 7.21 & 6.59 & 4.74 \\
\hline
\end{tabular}

ever, the relative differences between the ground instruments can be inferred from the table, although there may be geographical differences in the locations of the stations that may somewhat influence the results.

The MSR level 2 data spans 30 years of sequential satellite observations. In this period only 3 time intervals exist with a data gap of more than 2 days. This happened in the period 1995-1996 with gaps of 3.4, 3.0 and 4.5 days.

\section{Data assimilation}

The satellite instrument observations are combined with meteorological, chemical and dynamical knowledge of the atmosphere by using data assimilation. The data assimilation scheme used here is called TM3DAM and is described in Eskes et al. (2003). The chemistry-transport model used in this data assimilation is a simplified version of TM5 (Krol et al., 2005), which is driven by ECMWF analyses of wind, pressure and temperature fields. As input the MSR ozone values and the estimates of the measurement uncertainty are used. These uncertainties are described in Sect. 3.5. A quality screening is implemented to reject unrealistic ozone observations (i.e. below $50 \mathrm{DU}$ or above $700 \mathrm{DU}$ ) or unreliable ozone observations (measured with a solar zenith angle higher than $85^{\circ}$ ). Observations that deviate from the model forecasts more than either 3 times the observation uncertainty or 3 times the model uncertainty are also rejected. Because of this restriction and the assumption of unbiased observations, the satellite data has been corrected as described before.

The three-dimensional advection of ozone is described by the flux-based second order moments scheme of Prather et 
Table 5. Noise figures of the ground network compared to MSR level 2.

\begin{tabular}{lrr}
\hline Instrument type & $\begin{array}{r}\text { RMS7 } \\
\text { (DU) }\end{array}$ & $\begin{array}{r}\text { Number of } \\
\text { instruments }\end{array}$ \\
\hline All & 8.77 & 290 \\
Dobson & 8.62 & 109 \\
Brewer (all) & 8.92 & 87 \\
Brewer MKII & 9.10 & 38 \\
Brewer MKIII & 7.59 & 13 \\
Brewer MKIV & 9.08 & 34 \\
Brewer MKV & 10.26 & 2 \\
Filter & 13.48 & 59 \\
Microtops & 7.99 & 2 \\
\hline
\end{tabular}

al. (1986). The model is driven by 6-hourly meteorological fields (wind, surface pressure, and temperature) of the medium-range meteorological analyses of the ECMWF. The assimilation is using the ERA-40 reanalysis (1978-2001) as well as operational data sets (2002-2008). The 60 or 91 ECMWF hybrid layers between $0.01 \mathrm{hPa}$ and the surface have been converted into the 44 layers used in TM3DAM, whereby in the stratosphere and upper troposphere region all levels of the 60-layer definition are used. The horizontal resolution of the model version used in this study is $2 \times 3^{\circ}$. This relatively modest resolution is compensated by the practically non-diffusive Prather scheme (with 10 explicit ozone tracers for each grid cell), which allows the model to produce ozone features with a fair amount of detail. The output of the analyses is provided on a grid with a resolution of $1 \times 11 / 2^{\circ}$.

Ozone chemistry in the stratosphere is described by two parameterizations. One consists of a linearization of the gas-phase chemistry with respect to production and loss, the ozone amount, temperature and UV radiation. A second parameterization scheme accounts for heterogeneous ozone loss. This scheme introduces a three-dimensional chlorine activation tracer, which is formed when the temperature drops below the critical temperature of polar stratospheric cloud formation. Ozone breakdown occurs in the presence of the chlorine activation tracer, depending on the presence of sunlight. The rate of ozone decrease is described by an exponential decay, with a rate proportional to the amount of activation tracer below the critical temperature and with a minimal decay time of 12 days. The cold tracer is deactivated when light is present with a time scale of respectively 5 and 10 days on the Northern and Southern Hemisphere.

The total ozone data are assimilated in TM3DAM by applying a parameterized Kalman filter technique. In this approach the forecast error covariance matrix is written as a product of a time independent correlation matrix and a timedependent diagonal variance. The various parameters in the approach are fixed and are based on the forecast minus observation statistics accumulated over the period of one year
(2000) using GOME observations. This approach produces detailed and realistic time- and space-dependent forecast error distributions.

The data assimilation approach used for this work is based on the scheme described in (Eskes et al., 2003), but some improvements are made. The most important changes are:

1. The inclusion of a new ozone chemistry parameterisation Cariolle version 2.1 (Cariolle et al., 2007). This update of the Cariolle parameterisation has improved the forecast over Antarctica during the ozone hole season.

2. As it was no longer practical to perform the data assimilation on a per-orbit basis, a fixed $30 \mathrm{~min}$ data assimilation time step has been used.

3. The construction of super-observations from the multiple satellite instrument dataset. Previously the error of the super-observation was computed with the assumption of a constant observation error. In the present multisensor analysis an average observation error per instrument is introduced (see Table 4). Based on the correlations of the GOME observations in a single grid cell, earlier established by Eskes et al. (2003), the average error correlation is assumed to be $50 \%$. The superobservations are average satellite observations weighted with the inverse of their variances.

The quality control consisted of a comparison between the individual observations and the model forecast. When this difference exceeded 3 times the forecast error or the observation error, the observation is rejected. Only a few percent of all observations is rejected with this quality check.

One example drawn from the MSR ozone analysis data set is shown in Fig. 3, which shows the MSR ozone field derived for 15 April 1992 and 24 September 2002 at 12:00 UTC. These examples illustrate the resolution of the data set, which allows monitoring events like the split of the ozone hole in 2002. No discontinuity across the date line is present in the images, which is often seen in gridded level 2 data. The 6-hourly instantaneous and monthly mean ozone fields are available on the TEMIS web site, http://www.temis.nl/. For UV radiation studies the daily ozone fields at local noon are also made available on this web site. In Fig. 4 the average ozone mass deficit over Antarctica in the period 21-30 September, when the ozone depletion is usually at its maximum, is shown for the period 1978-2008. The ozone mass deficit is defined as the total amount of ozone needed to fill the ozone columns below $60^{\circ}$ South to a level of $220 \mathrm{DU}$. The period covered by the MSR data set shows the beginning of the ozone hole in the eighties when CFCs entered the stratosphere and the more or less stable period afterwards when the Montreal protocol was endorsed. Exceptional year was 2002 when the ozone hole broke up after the first major stratospheric warming observed in the southern hemisphere (see Fig. 3, and WMO, 2007). One part of the split vortex 


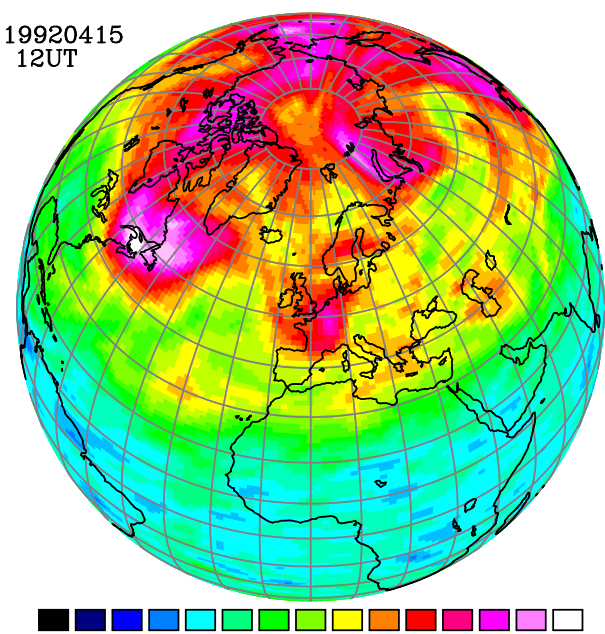

150175200225250275300325350375400425450475500

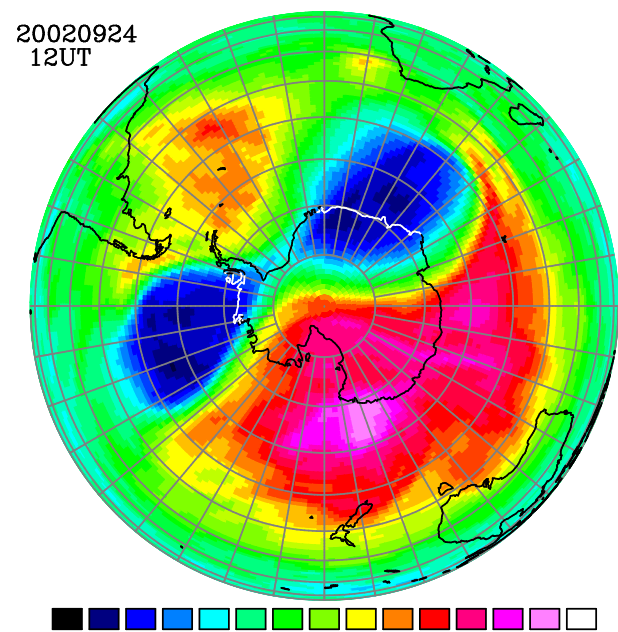

150175200225250275300325350375400425450475500

Fig. 3. Examples of the analysed MSR ozone field in DU. The left panel shows a low pressure system over Western Europe on 15 April 1992. The right panel shows the split ozone hole over Antarctica on 24 September 2002.

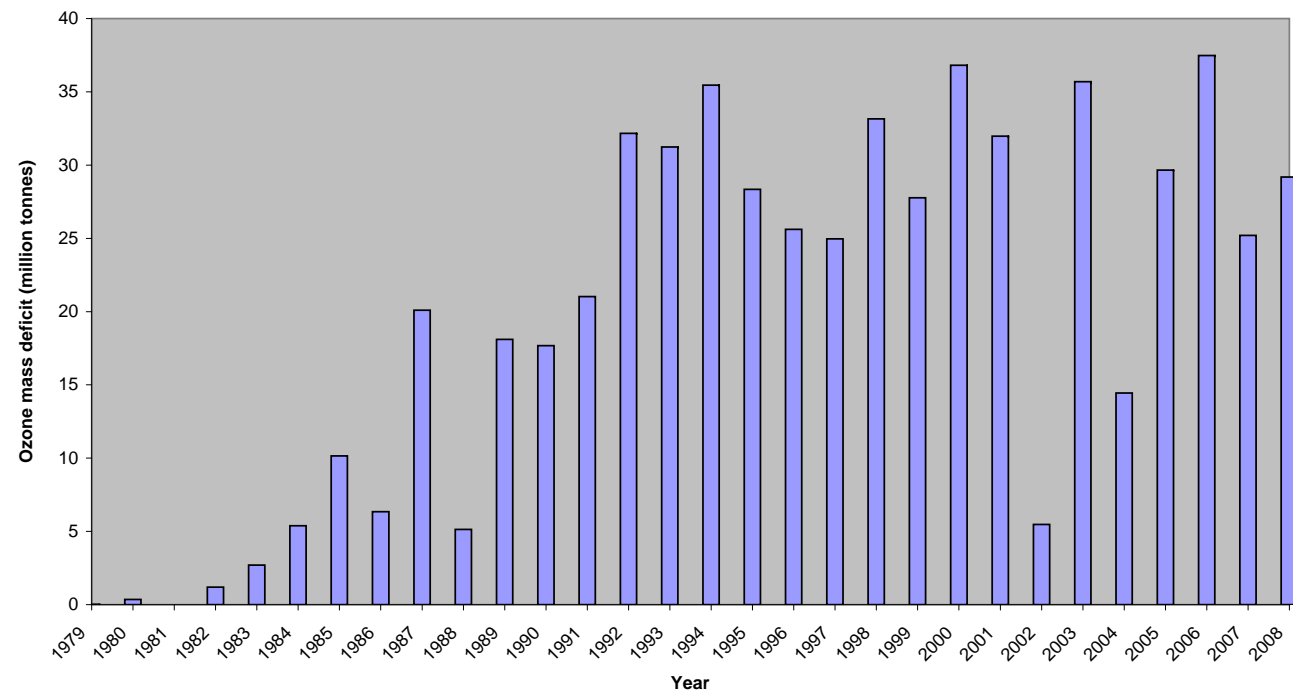

Fig. 4. The ozone mass deficit over Antarctica in the period 21-30 September based on the multi-sensor re-analysis (MSR) total ozone in the period 1979-2008.

dissolved quickly after this event. The maximum daily ozone deficit observed during the 30 year period was $42.2 \times 10^{9} \mathrm{~kg}$ on 26 September, 2003.

\section{Evaluation of the MSR data}

Figure 5 gives an example of the MSR level 4 data set compared to ground data: it shows the same time period and location as for Fig. 1. Where Fig. 1 clearly showed systematic deviations, most notable the seasonal cycles, in Fig. 5 no seasonal cycle or trends are visible. Still a small offset remains between MSR and the ground observations on this location, which can be caused by either the ground observations or the MSR. Therefore, the MSR data has been compared with all available ground observations from the WOUDC database. One might argue that these ground observations are already used in generating the MSR data, but at least it is a consistency check and it still shows the quality of a level 4 data set compared to the "ground truth". When fitting the MSR data to the ground observations the fitted offset was found to be smaller than $0.2 \mathrm{DU}$, and both the trend $(0.02 \mathrm{DU} /$ year) and seasonal variation (effective ozone temperature dependence of $-0.006 \mathrm{DU} /{ }^{\circ} \mathrm{K}$ ) were negligible. The geographical distribution of the offset between MSR level 4 data and individual ground stations is shown in Fig. 6. In Europe some stations 


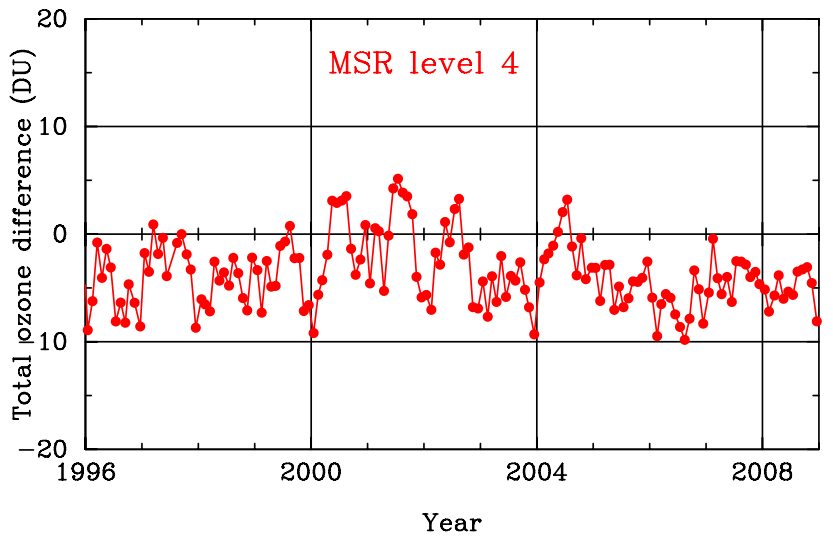

Fig. 5. Monthly averaged anomalies (satellite measurement minus ground measurement) for the overpass data of the MSR at the ground station De Bilt $\left(5.18^{\circ} \mathrm{E}, 52.1^{\circ} \mathrm{N}\right)$ in the Netherlands.

can no longer be distinguished due to its high concentrations of ground stations. On average no offset is present, and only a few outliers are visible. No systematic structures are obvious in the geographical distribution.

An important source of information for the evaluation of any data assimilation is the observation-minus-forecast $(\mathrm{OmF})$ and the observation-minus-analysis $(\mathrm{OmA})$ statistics produced by the TM3DAM analysis system ("forecast" is the model result just before assimilation and "analysis" is the assimilation result). This mechanism allows detection of sudden changes in the data quality and provides error estimates for the total ozone retrieval as well as the model performance. The analysis uncertainty is reported as a two-dimensional field, part of the analysis product. In the data assimilation the forecasts are calculated in sequential steps of half an hour. For assimilation of a single sensor, such as TOMS or OMI the observations at a certain location are typically once a day and therefore the OmF and OmA reflect a time step of 1 day. For the assimilation of SBUV only (e.g. beginning 1995), accounting for a correlation length of $500 \mathrm{~km}$, the revisit time is typically 1 week. For data assimilation of multiple sensors this is different, time steps between observations can range anything between half an hour and 1 day. This means that the $\mathrm{OmF}$ and $\mathrm{OmA}$, and therefore the data assimilation results, are more restrained by the observations. Typical $\mathrm{OmF}$ and OmA behaviour that has been checked are: (i) in general the OmA has to be smaller than the OmF, (ii) no geo-location or geo-parameter dependencies have to be visible, (iii) the RMS will mainly reflect the error distribution of the observations.

As example, the OmF and OmA are analyzed for January 2008 as function of location, latitude band, solar zenith angle, viewing angle, total ozone and cloud parameters. No significant systematic deviations were found. In Fig. 7 the geographical distribution of the OmF gridded for January 2008 is shown. In general the mean $\mathrm{OmF}$ is between -3 and +3 DU. In the northern latitudes some higher variations

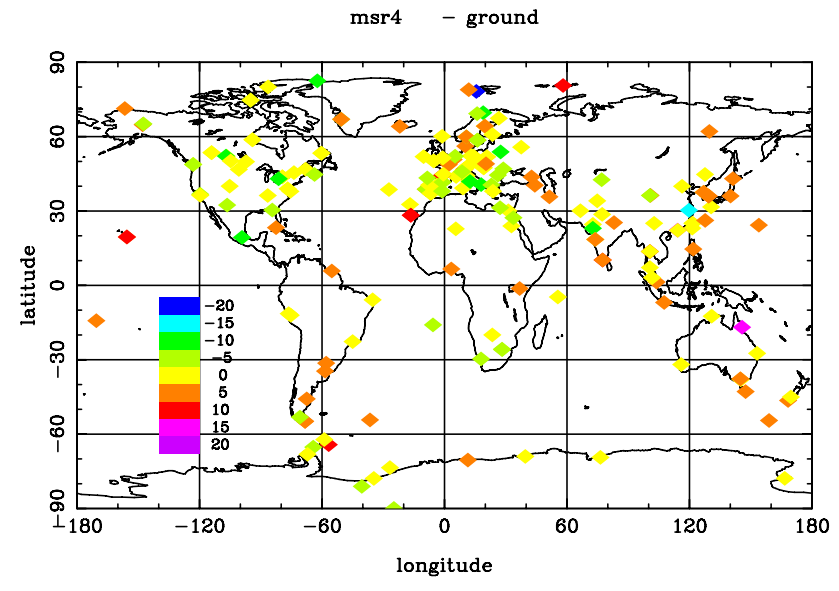

Fig. 6. Fitted offset (MSR-ground) between the MSR level 4 data and all selected ground measurement in the period 1978-2008.

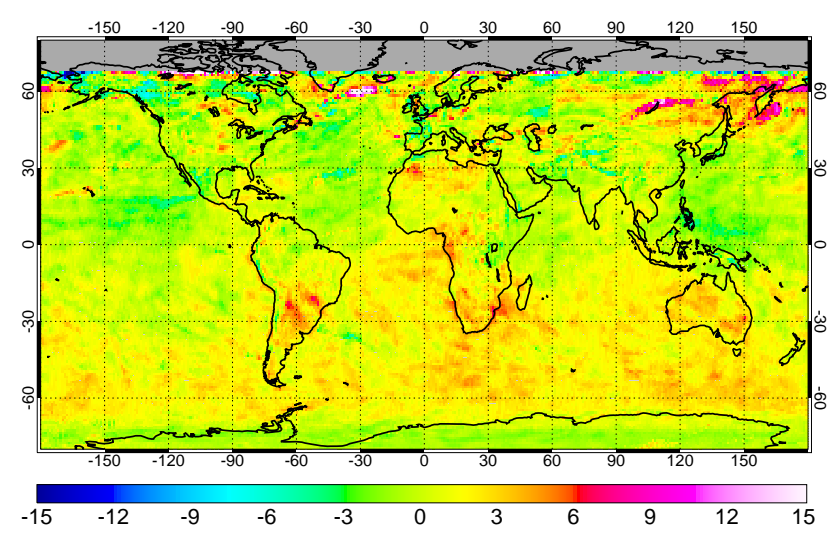

Fig. 7. Example of the global distribution, gridded on $1 \times 1^{\circ}$, of the observation-minus-forecast in DU of the MSR dataset averaged for the month January 2008. The MSR data for this month is based on satellite observations from GOME, SCIAMACHY, GOME2 and OMI.

are found caused by the strong natural variations around the North Pole in this time of the year. No obvious patterns as function of ground elevation or surface type were seen, and the patterns seem to be rather uncorrelated from one month to the next. The OmA for this month was much smaller than the $\mathrm{OmF}$ as is to be expected. The distribution of the OmF was found to be close to normal (Gaussian), which means that at least the largest contribution to the OmF error must closely agree with the assumption of Gaussian error distribution.

In Fig. 8 the latitude dependence of $\mathrm{OmF}$ and $\mathrm{OmA}$ is given. In addition the RMS value of the $\mathrm{OmF}$ is plotted. On average the root-mean-square difference between new satellite observations and the short-range model forecast ( 1 day) is small: about $6 \mathrm{DU}$, or roughly $2 \%$, for the tropics and mid-latitudes. This is comparable to the RMS values of the MSR level 2 data set compared to ground station measurements. For high Northern latitude the RMS increases, 


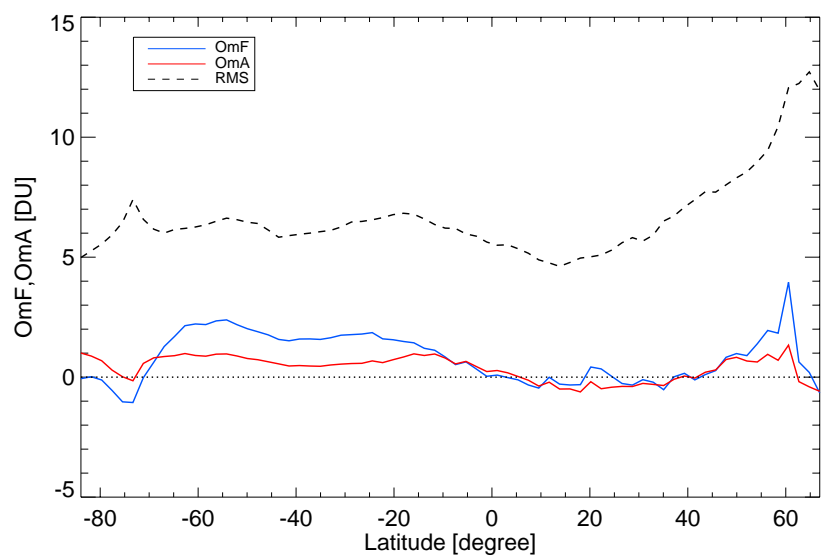

Fig. 8. Observation-minus-forecast in DU (blue line) and observation-minus-analysis (red line) as a function of latitude. The dashed black line represents the RMS value of the observationminus-forecast distribution. All data are averaged over January 2008.

which is related to high ozone variability in winter, and a corresponding increase of the representativity mismatch. The bias between the forecast and the columns is smaller than $1 \%$. The bias between analysis and the observations is in general smaller (about $1 \mathrm{DU}$ ), which shows the effect of the data assimilation. Compared to assimilation of the observations of the GOME instrument only, as shown earlier in Eskes et al. (2003) with almost the same data assimilation system, both RMS and bias are considerably decreased by using an improved retrieval for GOME and by using the full MSR level 2 dataset consisting of GDP, TOGOMI, SGP, TOSOMI, OMDOAO3, OMTO3, GOME2 for January 2008.

In Fig. 9 the OmF is shown as function of solar zenith angle, ozone, cloud fraction and viewing angle for January 2008. Again no large systematic effects are found and similar OmF, OmA and RMS values are found as earlier discussed for Fig. 8. For high solar zenith angles the RMS value increases, because these measurements are usually associated with the highly variable ozone concentrations in and around the polar vortex. In addition, the model bias is higher closer to the region of the polar night, where no satellite observations of ozone are performed. From the ozone dependence it follows that the model shows a slight tendency to underestimate the range of ozone values.

Similar results as shown in Fig. 9 are found for other months in the data set. The period from June 1993 till May 1995 is of special interest because the satellite observations are sparse as only SBUV9d and SBUV11 performed measurements. Note that in this period the forecast of the $\mathrm{OmF}$ is for $24 \mathrm{~h}$. Also in this period the mean OmF and OmA values are small (less than 1\%), but the RMS values are higher, up to $4-5 \%$. For this period the forecast error is likely to be higher because of the low coverage of the Earth by the sparse SBUV observations.
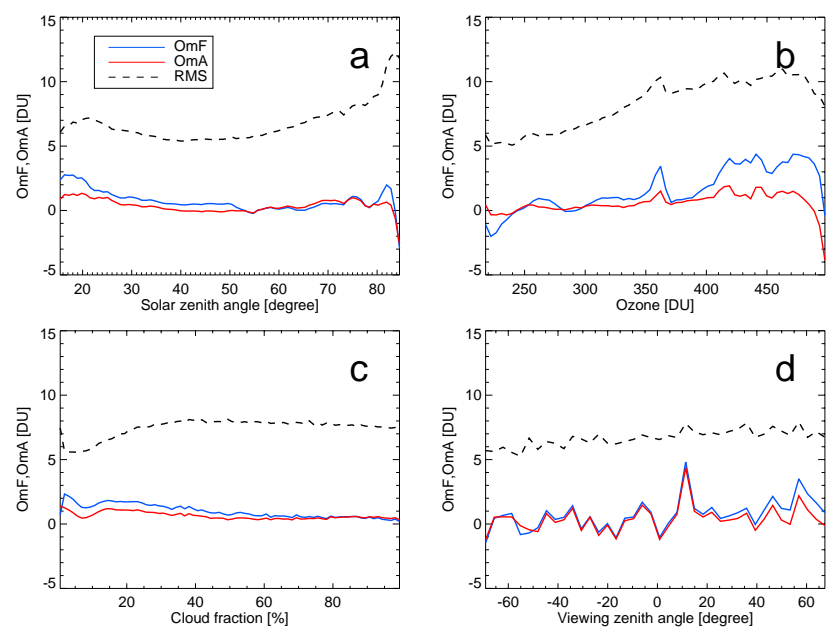

Fig. 9. The observation-minus-forecast in DU (blue line) and the observation-minus-analysis (red line) as a function of solar zenith angle (a), observed ozone (b), cloud fraction (c), and viewing zenith angle (d). The dashed line represents the RMS value of the observation-minus-forecast distribution. All data are averaged over January 2008.

The assumption has been made that different retrieval datasets from the same satellite instrument have uncorrelated errors. To check this assumption the average correlation of the ozone differences (between satellite observation and analysis) is calculated for different algorithms but from the same satellite observation. Based on the OmA statistics the average correlation of the algorithm pairs TOGOMI/GDP, TOSOMI/SGP and OMDOAO3/OMTO3 were estimated as, respectively, $0.22 \pm 0.10,0.20 \pm 0.02$ and $0.22 \pm 0.03$ for April 2007 and $0.34 \pm 0.17,0.30 \pm 0.09$ and $0.14 \pm 0.03$ for the month December 2008. From this low correlation we conclude that using the observations of the mentioned algorithm pairs as independent data sets in the data assimilation is a valid choice.

\section{Conclusions and outlook}

By exploiting on the one hand the accuracy and large number of ground measurements and on the other hand the global coverage of satellite observations, a data set is created of an optimal estimate of the global distribution of total ozone in a period of 30 years. The data is created in two steps: firstly, correcting small systematic biases in the satellite data by taking the ground observation on average as the true value. Secondly, all satellite data is assimilated with a Kalman filter technique in order to have a consistent data set with a regular spatial grid of $1 \times 1 \frac{1}{2} 2^{\circ}$ and a time step of $6 \mathrm{~h}$ throughout the complete 30 -year period. 
Several assimilation-based long-term ozone records exist, and have been reported in the literature. Dethof and Holm (2004), report on the quality of a 45-year reanalysis (ERA40) of ozone performed with the ECMWF model. This work is based on previous data versions of TOMS (version 7) and SBUV (version 6), and no additional corrections were applied to account for drifts and offsets against surface data. The 45 years can be divided in four different time windows, depending on the availability of satellite data. The quality of the analyses differs from one window to the next, which complicates the use of this reanalysis for trend studies.

Brunner et al. (2006b) provide a quasi-3D ozone time series for the period 1979-2004, based on the NIWA total ozone dataset constructed from TOMS/SBUV v8 and GOME total ozone observations (Bodeker et al., 2001, 2005). As in the MSR dataset, Dobson ground observations were used to remove offsets and drifts in the satellite data. However, the MSR uses both Dobson and Brewer ground observations for correcting the satellite observations, and these corrections are based on dependencies of parameters directly related to retrieval errors. Important in correcting satellite data is the fitting against the effective ozone temperature, which is a critical parameter for total ozone retrievals. This is a novelty in the MSR data set. The analysis by Brunner et al. (2006b) is based on a two-dimensional equivalent latitude - potential temperature Kalman filter approach. Brunner shows that realistic 3-D ozone distributions can be reconstructed on the basis of 2-D ozone column information only. In the MSR the analyses are performed with a full 3-D model, which avoids errors that may result from the 2-D-3-D mapping. However, the data presented are restricted to the 2-D ozone column field, because this is strongly determined by the satellite observations.

Compared to existing long-term datasets, the MSR data is based on more satellite data sets by including all available retrievals of the recent satellite instruments GOME, SCIAMACHY, OMI, and GOME-2.

Currently, the MSR data set is used by research institutes for the creation of long-term time series of UV radiance, which will be compared with ground measurements and used for trend analysis. The data is also of interest for climate research, for atmospheric chemistry modelling, for analyzing trends in ozone and for the study of the recovery of the ozone hole.

The OmA of this dataset is less than $1 \%$, which is better than for the assimilation of observations of a single sensor. The model influence as estimated by the difference between $\mathrm{OmF}$ and OmA is in general very small. Therefore, even for small periods of a couple of days with no data, the bias will remain within $1 \%$. As discussed earlier, this holds also for the period with only sparse SBUV observations. The longest gap in our level 2 data series is 4.5 days. The RMS errors are around $2 \%$, which is low since the RMS errors contain representativity errors, forecast errors and instrumental noise.
It has been shown that the MSR level 2 data presented no drift and an insignificant SZA and effective ozone temperature dependence as compare to the ground observations (see Table 2). The final MSR level 4 data is on average comparable with the ground data: the fitted offset, trend and seasonality in the comparison between MSR level 4 data and all observations of the WOUDC data base were negligible. The maximum fitted offset is $0.2 \mathrm{DU}$. All the systematic effects found in the satellite data are removed by the simple corrections (using a few basic parameters) applied to the satellite observations in the period 1978-2008. Especially for the last years, the corrections applied to the satellite data are expected to improve when more data will become available in the WOUDC database.

The combination of the different satellite data into a coherent MSR level 2 data revealed that there are systematic differences between all the total ozone satellite products and the network of ground stations. By combining the satellite data and model knowledge using data assimilation and by using the ground data as a reference the aim was to obtain the best possible data set for the total ozone in the atmosphere by combining all available ozone column information. It is however difficult to draw conclusions about the quality of individual dataset, since our work is based on the assumption that the ground observations are on average without mean bias, seasonal bias or trends. We hope that this work will stimulate the research in retrieval algorithms, both for the satellite and the ground instruments. For future missions we recommend to plan a long repeat cycle of the satellite orbit in such a way that the overpass dataset of a single ground station contains all viewing angles of the satellite.

The authors are aware that at the time of the writing of this paper development is still on-going for the improvement of the retrieval products of in particular GOME-2 and OMI, which are relatively new satellite instruments. But research is also being done to improve the other satellite products, so certain conclusions about their quality will probably be quickly outdated. Therefore, as new developments become available, also the MSR data set is planned to be regularly reprocessed to incorporate the latest versions of satellite and ground data.

\section{Appendix A}

\section{Satellite datasets}

For each satellite dataset the version number, the origin of the data and a reference is shown. If part of the dataset has been rejected, this is also shown here. The corrections applied to each dataset are shown at the end of each entry. In all formulae $X$ is the total ozone in DU, $T_{\text {eff }}$ is the effective ozone temperature in degrees Celsius and angles are expressed in degrees. MJD is the number of years since 2000 . 


\section{A1 TOMS2a}

- Processing: NASA. (Version: 8).

- Downloaded from: http://disc.sci.gsfc.nasa.gov/data/ datapool/TOMS/Level_2/.

- Reference: Bhartia et al., 2002.

- All data with ozone values $>0$ have been used.

- Corrections applied: effective temperature and offset.

- $X_{\text {cor }}=X_{\text {sat }}-0.462 \cdot\left(T_{\text {eff }}+46.3\right)-2.066$.

\section{A2 TOMS2b}

- Processing: NASA (Version: 8).

- Downloaded from: http://disc.sci.gsfc.nasa.gov/data/ datapool/TOMS/Level_2/.

- Reference: Bhartia et al., 2002.

- All data with ozone values $>0$ have been used.

- Corrections found: effective ozone temperature, VZA (not linear), trend (from 2000) and offset.

- Before 1 January 2000: $X_{\text {corr }}=X_{\text {sat }}-0.447$. $\left(T_{\text {eff }}+46.3\right)+0.839+f($ pixel $)$.

- From 1 January 2000: $\quad X_{\text {corr }}=X_{\text {sat }}-0.728$. $\left(T_{\text {eff }}+46.3\right)+5.093 \cdot M J D-8.098+f($ pixel $)$.

- The viewing zenith angle correction $f$ (pixel) as function of the across-track pixel is shown in Fig. A1.

\section{A3 SBUV07, SBUV9a, SBUV9d, SBUV11, SBUV16}

- Processing: NOAA/NASA Ozone Processing Team.

- Data from: DVD-ROM "SBUV Version 8" NOAA/NASA.

- Reference: Miller et al., 2002; Taylor et al., 2003.

- All data flagged as "Good retrieval" have been used.

- SBUV data have been corrected for temperature only.

- SBUV07: $X_{\text {cor }}=X_{\text {sat }}-0.153 \cdot\left(T_{\text {eff }}+46.3\right)-3.431$

- SBUV9a: $X_{\text {cor }}=X_{\text {sat }}-0.376 \cdot\left(T_{\text {eff }}+46.3\right)-2.418$

- SBUV9d: $X_{\text {cor }}=X_{\text {sat }}-0.196 \cdot\left(T_{\text {eff }}+46.3\right)-0.823$

- SBUV11: $X_{\text {cor }}=X_{\text {sat }}-0.258 \cdot\left(T_{\text {eff }}+46.3\right)-2.360$

- SBUV16: $X_{\text {cor }}=X_{\text {sat }}-0.467 \cdot\left(T_{\text {eff }}+46.3\right)-6.155$

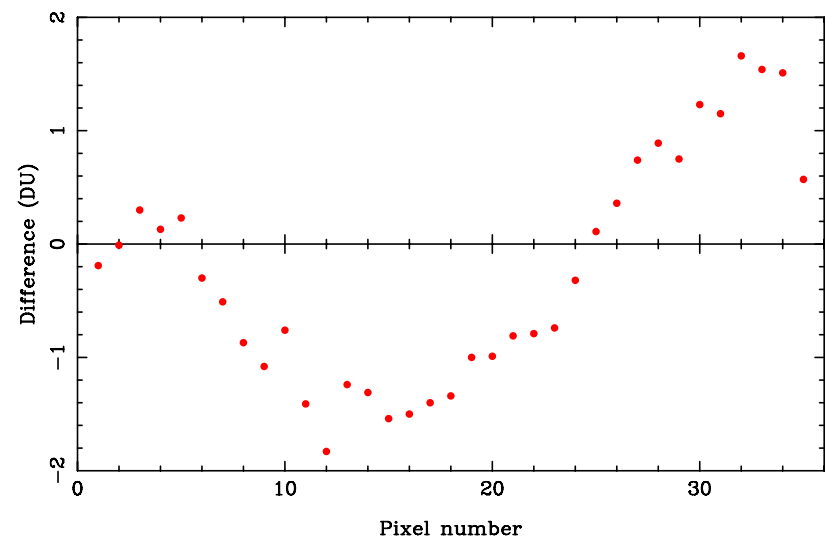

Fig. A1. The viewing angle correction for TOMS2b.

\section{A4 GDP}

- Processing: DLR/ESA. (Version: 4.00 and 4.10)

- Data from: http://nlsciadc.knmi.nl/

- Reference: Van Roozendael et al., 2006; Balis et al., 2007a.

- Back-scan pixels have been ignored; ozone values $<0$ have been ignored.

- Both a SZA, VZA correction has been applied, the last nonlinear (pixel based, thee values).

- Deleted: June-September 2003.

- $X_{\text {cor }}=X_{\text {sat }}-0.114 \cdot(\mathrm{SZA}-30)+2.933+f($ pixel $)$.

- The viewing zenith angle correction $f$ (pixel) as function of the across-track pixel is given by Table A1.

\section{A5 TOGOMI}

- Processing: KNMI. (Version 1.2, level 1: version 3.02).

- Data from: http://www.temis.nl/protocols/O3total.html.

- Reference: Valks et al., 2004.

- All data have been used (there are no back-scan pixels in the dataset).

- A nonlinear VZA dependence has been corrected (pixel based, six values).

- $X_{\text {cor }}=X_{\text {sat }}+1.649+f($ pixel $)$.

- The viewing zenith angle correction $f$ (pixel) as function of the across-track pixel is given by Table A2. For the nadir-static and polar viewing angle mode too little data exists to obtain a reliable correction as function of viewing angle. 
Table A1. The viewing angle as function of pixel for the GDP data set.

\begin{tabular}{lrrr}
\hline Pixel & East & Centre & West \\
\hline Correction (DU) & -1.17 & 0.42 & 0.89 \\
\hline
\end{tabular}

Table A2. The correction (DU) as function of view angle for the TOGOMI data set.

\begin{tabular}{lrrr}
\hline Mode & \multicolumn{3}{c}{ Pixel } \\
\cline { 2 - 4 } & East & Centre & West \\
\hline Normal & -1.76 & 0.40 & 1.47 \\
Small-swath & 0.04 & 0.99 & 0.56 \\
Nadir static & 0 & 0 & 0 \\
Polar viewing & 0 & 0 & 0 \\
\hline
\end{tabular}

\section{A6 SGP}

- Processing: DLR/ESA (Version 3.01).

- Data from: http://nlsciadc.knmi.nl/.

- Reference: Lerot et al., 2009; Lambert et al., 2007.

- Back-scan pixels have been ignored; ozone values $<0$ have been ignored.

- This product shows a significant trend. A small VZA dependence has also been corrected.

$-X_{\mathrm{cor}}=X_{\mathrm{sat}}-0.016 \cdot \mathrm{VZA}-8.031+1.090 \cdot \mathrm{MJD}$

\section{A7 TOSOMI}

- Processing: KNMI (version 0.43, level 1: version 6.03)

- Data from: http://www.temis.nl/protocols/O3total.html.

- Reference: Eskes et al., 2005.

- All data have been used (there are no back-scan pixels in the dataset).

- This product has a trend similar to SGP. Also small SZA and VZA corrections have been applied.

- Deleted: 20 December 2002-29 December 2002.

- $X_{\text {cor }}=X_{\text {sat }}-0.284 \cdot(\mathrm{SZA}-30)+0.049 \cdot \mathrm{VZA}+1.039$. $\mathrm{MJD}+2.322$

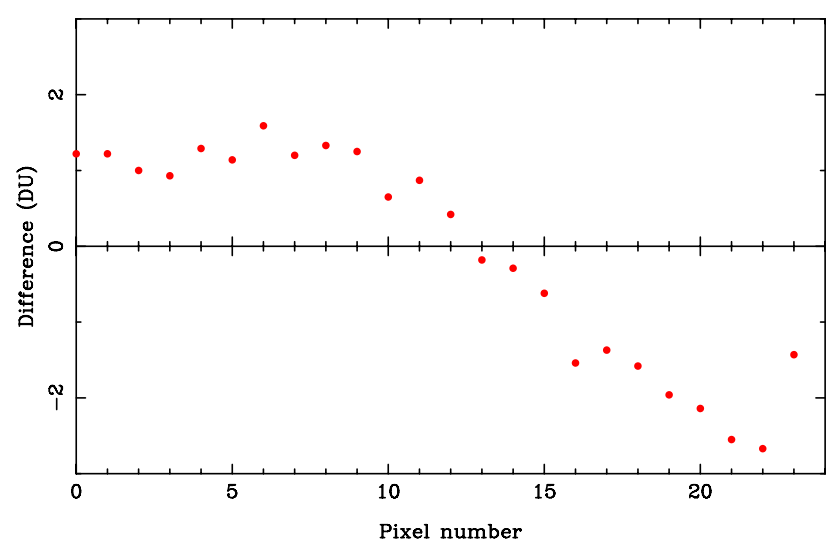

Fig. A2. The viewing angle correction for GOME2.

\section{A8 OMDOAO3}

- Processing: NASA (Version: 003, level 1: collection 3).

- Data from: http://www.temis.nl/protocols/O3total.html.

- Reference: Veefkind et al., 2006; Balis et al., 2007b; McPeters et al., 2008.

- Pixels have been deleted if ozone values are zero, or the RMS errors are higher than $10 \mathrm{DU}$, or the logical sum of "ProcessingQualityFlags" and "10911" is nonzero.

- The instrument is developing "row anomalies". Bad rows have been deleted according to the information on http://www.knmi.nl/omi/research/product/ rowanomaly-background.php. A procedure for the "zoom mode" has been indirectly derived from this information.

- Corrections: SZA (not linear), temperature, trend, offset.

$-X_{\mathrm{cor}}=X_{\mathrm{sat}}-0.00189 \cdot(\mathrm{SZA}-30)^{2}+0.300$. $\left(T_{\text {eff }}+46.3\right)-0.358 \cdot \mathrm{MJD}+5.379$

\section{A9 OMTO3}

- Processing: NASA. (Version 3, level 1: collection 3).

- Data from: http://disc.sci.gsfc.nasa.gov/Aura/ data-holdings/OMI/omto3_v003.shtml.

- Reference: Bhartia et al., 2002; Balis et al., 2007b; McPeters et al., 2008.

- Pixels have been deleted if total ozone is less then 1 DU, or the logical sum of "Quality Flags" and hexadecimal "FFF6" is nonzero.

- The instrument is developing "row anomalies". See OMDOA3. 
- All data before 9 September 2004 have been ignored.

- Corrections: temperature, offset.

- $X_{\text {cor }}=X_{\text {sat }}-0.282 \cdot\left(T_{\text {eff }}+46.3\right)+2.578$

\section{A10 GOME2}

- Processing: DLR/EUMETSAT. (Versions: GDP 4.3, using reprocessed level1B-R1 v4.0 data).

- Data from: DLR (provided by P. Valks).

- Reference: Valks et al., 2008; http://lap.physics.auth.gr/ eumetsat/.

- GOME-2 appears to have a significant trend. Also corrections for SZA and VZA (nonlinear) have been applied.

$-X_{\mathrm{cor}}=X_{\mathrm{sat}}-0.164 \cdot \mathrm{SZA}-2.186 \cdot \mathrm{MJD}+26.998+$ $f$ (pixel).

- The viewing zenith angle correction $f$ (pixel) as function of the across-track pixel is shown in Fig. A2.

Acknowledgements. The authors would like to thank Pieter Valks for providing us the GOME-2 ozone column data. The authors thank the WOUDC and the ground station operators for providing the ozone column data at http://www.woudc.org/. Furthermore, the authors thank the agencies NASA, NOAA, ESA, and EUMETSAT for making respectively the TOMS and OMI data, the SBUV data, the GOME and SCIAMACHY data, and the GOME-2 data publicly available at their web sites. We thank Piet Stammes for his help with the manuscript.

Edited by: M. Van Roozendael

\section{References}

Balis, D., Lambert, J.-C., Van Roozendael, M., Spurr, R., Loyola, D., Livschitz, Y., Valks, P., Amiridis, V., Gerard, P., Granville, J., and Zehner, C.: Ten years of GOME/ERS-2 total ozone data - The new GOME data processor (GDP) version 4: 2. Groundbased validation and comparisons with TOMS V7/V8, J. Geophys. Res., 111, D07307, doi:10.1029/2005JD006376, 2007a.

Balis, D., Kroon, M., Koukouli, M. E., Brinksma, E. J., Labow, G., Veefkind, J. P., and McPeters, R. D.: Validation of Ozone Monitoring Instrument total ozone column measurements using Brewer and Dobson spectrophotometer ground-based observations, J. Geophys. Res., 112, D24S46, doi:10.1029/2007JD008796, 2007b.

Bhartia, P. K. and Wellemeyer, C.: TOMS-V8 total O3 algorithm, in OMI Algorithm Theoretical Basis Document, vol. II, OMI Ozone Products, ATBD-OMI-02, edited by P. K. Bhartia, 15-31, NASA Goddard Space Flight Cent., Greenbelt, Md., http://eospso.gsfc. nasa.gov/eos_homepage/for_scientists/atbd/, 2002.

Bodeker, G. E., Scott, J. C., Kreher, K., and McKenzie, R. L.: Global ozone trends in potential vorticity coordinates using TOMS and GOME intercompared against the Dobson network: 1978-1998, J. Geophys. Res., 106(D19), 23029-23042, 2001.
Bodeker, G. E., Shiona, H., and Eskes, H.: Indicators of Antarctic ozone depletion, Atmos. Chem. Phys., 5, 2603-2615, doi:10.5194/acp-5-2603-2005, 2005.

Bovensmann, H., Burrows, J. P., Buchwitz, M., Frerick, J., Noël, S., Rozanov, V. V., Chance, K. V., and Goede, A. P. H.: SCIAMACHY: Mission Objectives and Measurement Modes, J. Atmos. Sci., 56, 127-150, 1999.

Brunner, D., Staehelin, J., Maeder, J. A., Wohltmann, I., and Bodeker, G. E.: Variability and trends in total and vertically resolved stratospheric ozone based on the CATO ozone data set, Atmos. Chem. Phys., 6, 4985-5008, doi:10.5194/acp-6-49852006, 2006a.

Brunner, D., Staehelin, J., Künsch, H.-R., and Bodeker, G. E.: A Kalman filter reconstruction of the vertical ozone distribution in an equivalent latitude-potential temperature framework from TOMS/GOME/SBUV total ozone observations, J. Geophys. Res., 111, D12308, doi:10.1029/2005JD006279, 2006 b.

Burrows, J. P., Weber, M., Buchwitz, M., Rozanov, V., LadstätterWeißenmayer, A., Richter, A., De Beek, R., Hoogen, R., Bramstedt, K., Eichmann, K. U., Eisinger, M., and Perner, D.: The Global Ozone Monitoring Experiment (GOME): Mission Concept and First Scientific Results, J. Atmos. Sci., 56, 151-175, 1999.

Callies, J., Corpaccioli, E., Eisinger, M., Hahne, A., and Lefebvre, A.: GOME-2 - Metop's Second Generation sensor for Operational Ozone Monitoring, ESA Bulletin, 102, 2000

Cariolle, D. and Teyssèdre, H.: A revised linear ozone photochemistry parameterization for use in transport and general circulation models: multi-annual simulations, Atmos. Chem. Phys., 7, 2183-2196, doi:10.5194/acp-7-2183-2007, 2007.

Derber, J. C. and Wu, W.-S.: The Use of TOVS Cloud-Cleared Radiances in the NCEP SSI Analysis System, Mon. Weather Rev., 126, 2287-2299, 1998.

Dethof, A. and Hólm, E. V.: Ozone assimilation in the ERA-40 reanalysis project, Q. J. Roy. Meteor. Soc., 130, 2851-2872, 2004.

Eskes, H. J., van Velthoven, P. F. J., Valks, P. J. M. and Kelder, H. M.: Assimilation of GOME total ozone satellite observations in a three-dimensional tracer transport model, Q. J. Roy. Meteorol. Soc., 129, 1663-1681, 2003.

Eskes, H. J., van der A, R. J., Brinksma, E. J., Veefkind, J. P., de Haan, J. F., and Valks, P. J. M.: Retrieval and validation of ozone columns derived from measurements of SCIAMACHY on Envisat, Atmos. Chem. Phys. Discuss., 5, 44294475, doi:10.5194/acpd-5-4429-2005, 2005.

Fioletov, V. E., Bodeker, G. E., Miller, A. J., McPeters, R. D., and Stolarski, R. S.: Global and zonal total ozone variations estimated from ground-based and satellite measurements: 1964-2000, J. Geophys. Res 107(D22), 4647, doi:10.1029/2001JD001350, 2002.

Fioletov, V. E., Labow, G., Evans, R., Hare, E. W., Köhler, U., McElroy, C. T., Miyagawa, K., Redondas, A., Savastiouk, V., Shalamyansky, A. M., Staehelin, J., Vanicek, K., and Weber, M.: Performance of the ground-based total ozone network assessed using satellite data, J. Geophys. Res., 113, D14313, doi:10.1029/2008JD009809, 2008.

Fortuin, J. P. F. and Kelder, H.: "An ozone climatology base on ozonesonde and satellite measurements", J. Geophys. Res., 103, 31709-31734, available at: http://www.temis.nl/data/fortuin. html, 1998. 
Geer, A. J., Lahoz, W. A., Bekki, S., Bormann, N., Errera, Q., Eskes, H. J., Fonteyn, D., Jackson, D. R., Juckes, M. N., Massart, S., Peuch, V.-H., Rharmili, S., and Segers, A.: The ASSET intercomparison of ozone analyses: method and first results, Atmos. Chem. Phys., 6, 5445-5474, doi:10.5194/acp-6-5445-2006, 2006.

Harris, N. R. P., Kyrö, E., Staehelin, J., Brunner, D., Andersen, S.B., Godin-Beekmann, S., Dhomse, S., Hadjinicolaou, P., Hansen, G., Isaksen, I., Jrrar, A., Karpetchko, A., Kivi, R., Knudsen, B., Krizan, P., Lastovicka, J., Maeder, J., Orsolini, Y., Pyle, J. A., Rex, M., Vanicek, K., Weber, M., Wohltmann, I., Zanis, P., and Zerefos, C.: Ozone trends at northern mid- and high latitudes - a European perspective, Ann. Geophys., 26, 1207-1220, doi:10.5194/angeo-26-1207-2008, 2008.

Kerr, J. B.: New methodology for deriving total ozone and other atmospheric variables from Brewer spectrophotometer direct sun spectra, J. Geophys. Res., 107(D23), 4731, doi:10.1029/2001JD001227, 2002.

Kiesewetter, G., B.-M. Sinnhuber, M. Vountas, M. Weber, and J. P. Burrows, A long-term stratospheric ozone data set from assimilation of satellite observations: High-latitude ozone anomalies, J. Geophys. Res., 115, D10307, doi:10.1029/2009JD013362, 2010.

Krol, M., Houweling, S., Bregman, B., van den Broek, M., Segers, A., van Velthoven, P., Peters, W., Dentener, F., and Bergamaschi, P.: The two-way nested global chemistry-transport zoom model TM5: algorithm and applications, Atmos. Chem. Phys., 5, 417432, doi:10.5194/acp-5-417-2005, 2005.

Krzyścin, J. W.: Statistical reconstruction of daily total ozone over Europe 1950 to 2004, J. Geophys. Res., 113, D07112, doi:10.1029/2007JD008881, 2008.

Lambert, J.-C., Granville, J., Lerot, C., Gerard, P., Fayt, C., Van Roozendael, M. and the ACVT/GBMCD Ozone Column Team: GDP 4.0 transfer to SGP 3.0 for SCIAMACHY ozone column processing: verification with SDOAS/GDOAS prototype algorithms and delta-validation with NDACC and WOUDC network data, Proceedings of the Third Workshop on the Atmospheric Chemistry Validation of ENVISAT (ACVE-3), 4-7 Dec. 2006, ESA/ESRIN, Frascati, Italy, ESA Publications Division Special Publication SP-642 (CD), 2007.

Lerot, C., Van Roozendael, M., van Geffen, J., van Gent, J., Fayt, C., Spurr, R., Lichtenberg, G., and von Bargen, A.: Six years of total ozone column measurements from SCIAMACHY nadir observations, Atmos. Meas. Tech., 2, 87-98, doi:10.5194/amt-287-2009, 2009.

Levelt, P. F., van den Oord, G. H. J., Dobber, M. R., Mälkki, A., Visser, H., de Vries, J., Stammes, P., Lundell, J., and Saari, H.: The Ozone Monitoring Instrument, IEEE T. Geoscu. Remote, 44(5), 1093-1101, doi:10.1109/TGRS.2006.872333, 2006.

Lindfors, A., Tanskanen, A., Arola, A., van der A, R., Bais, A., Feister, U., Janouch, M., Josefsson, W., Koskela, T., Lakkala, K., den Outer, P. N., Smedley, A. R. D., Slaper, H., and Webb, A. R.: The PROMOTE UV Record: Toward a Global Satellite-Based Climatology of Surface Ultraviolet Irradiance, IEEE Journal of Selected Topics in Applied Earth Observations and Remote Sensing, 2(3), 207-212, doi:10.1109/JSTARS.2009.2030876, 2009.

Mäder, J. A., Staehelin, J., Brunner, D., Stahel, W. A., Wohltmann, I., and Peter, T.: Statistical modeling of total ozone: Selection of appropriate explanatory variables, J. Geophys. Res., 112, D11108, doi:10.1029/2006JD007694, 2007.
McPeters, R. D. and Labow, G. J.: An assessment of the accuracy of 14.5 years of Nimbus 7 TOMS version 7 ozone data by comparison with the Dobson network, Geophys. Res. Lett., 23(25), 3695-3698, 1996.

McPeters, R., Kroon, M., Labow, G., Brinksma, E., Balis, D., Petropavlovskikh, I., Veefkind, J. P., Bhartia, P. K., and Levelt, P. F.: Validation of the Aura Ozone Monitoring Instrument total column ozone product, J. Geophys. Res., 113, D15S14, doi:10.1029/2007JD008802, 2008.

Miller, A. J., Nagatani, R. M., Flynn, L. E., Kondragunta, S., Beach, E., Stolarski, R., McPeters, R. D., Bhartia, P. K., DeLand, M. T., Jackman, C. H., Wuebbles, D. J., Patten, K. O., and Cebula, R. P.: A cohesive total ozone data set from the SBUV(/2) satellite system, J. Geophys. Res., 107(D23), 4701, doi:10.1029/2001JD000853, 2002.

Prather, M. J.: Numerical advection by conservation of ozone data in weather-prediction models, Q. J. Roy. Meteorol. Soc., 122, 1545-1571, 1986.

Randel, W. J., Shine, K. P., Austin, J., Barnett, J., Claud, C., Gillett, N. P., Keckhut, P., Langematz, U., Lin, R., Long, C., Mears, C., Miller, A., Nash, J., Seidel, D. J., Thompson, D. W. J., Wu, F., and Yoden, S.: An update of observed stratospheric temperature trends, J. Geophys. Res., 114, D02107, doi:10.1029/2008JD010421, 2009.

Redondas, A. and Cede, A.: Brewer algorithm sensitivity analysis, SAUNA workshop, Puerto de la Cruz, Tenerife, November, 2006.

Reinsel, C. G., Miller, A. J., Weatherhead, E. C., Flynn, L. E., Nagatani, R. M., Tiao, G. C., and Wuebbles, D. J.: Trend analysis of total ozone data for turn- around and dynamical contributions, J. Geophys. Res., 110, D16306, doi:10.1029/2004JD004662, 2005.

Stajner, I., Wargan, K., Pawson, S., Hayashi, H., Chang, L.-P., Hudman, R. C., Froidevaux, L., Livesey, N., Levelt, P. F., Thompson, A. M., Tarasick, D. W., Stübi, R., Andersen, S. B., Yela, M., König-Langlo, G., Schmidlin, F. J., and Witte, J. C.: Assimilated ozone from EOS-Aura: Evaluation of the tropopause region and tropospheric columns, J. Geophys. Res., 113, D16S32, doi:10.1029/2007JD008863, 2008.

Staehelin, J., Harris N. R. P., Appenzeller, C., and Eberhard, J.: Ozone Trends: A Review, Rev. Geophys., 39(2), 231-290, 2001.

Staehelin, J., Kerr, J., Evans, R., and Vanicek, K.: Comparison of total ozone measurements of Dobson and Brewer spectrophotometers and recommended transfer functions, Tech. Rep., WMO, World Meteorological Organization Global Atmosphere Watch (WMO-GAW) Report 149, 2003.

Stolarski, R. S., Bloomfield, P., McPeters, R. D., and Herman, J. R.: Total Ozone trends deduced from Nimbus 7 Toms data, Geophys. Res. Lett., 18(6), 1015-1018, 1991.

Stolarski, R. S., Labow, G. J., and McPeters, R. D.: Springtime Antarctic total ozone measurements in the early 1970s from the BUV instrument on Nimbus 4, Geophys. Res. Lett., 24(5), 591594, 1997.

Stolarski, R. S. and Frith, S. M.: Search for evidence of trend slowdown in the long-term TOMS/SBUV total ozone data record: the importance of instrument drift uncertainty, Atmos. Chem. Phys., 6, 4057-4065, doi:10.5194/acp-6-4057-2006, 2006a.

Stolarski, R. S., Douglass, A. R., Steenrod, S., and Pawson, S.: Trends in stratospheric ozone: Lessons learned from a 3-D chemical transport model, J. Atmos. Sci., 63, 1028-1041, 2006 b. 
Taylor, S. L., Cebula, R. P., Deland, M. T., Huang, L.-K., Stolarski, R. S., and McPeters, R. D.: Improved calibration of NOAA-9 and NOAA-11 SBUV/2 total ozone data using inflight validation methods, Int. J. Remote Sens., 24.2, 315-328, doi:10.1080/01431160304977, 2003.

Valks, P. J. M., De Haan, J. F., Veefkind, J. P., Van Oss, R. F., and Balis, D. S.: TOGOMI: An improved total ozone retrieval algorithm for GOME, XX Quadrennial Ozone Symposium, 1/6/2004-8/6/2004, edited by: Zerefos, C. S., Athens, University of Athens, 129-130, 2004.

Valks, P. J. M., Loyola, D., Hao, N., and Rix, M.: Algorithm Theoretical Baseline Document for GOME-2 total column products of ozone, minor trace gases, and cloud properties, DLR/GOME2/ATBD/01, 2008.

Van Roozendael, M., Loyola, D., Spurr, R., Balis, D., Lambert, J.-C., Livschitz, Y., Valks, P., Ruppert, T., Kenter, P., Fayt, C., and Zehner, C.: Ten years of GOME/ERS-2 total ozone data - The new GOME data processor (GDP) version 4: 1. Algorithm description, J. Geophys. Res., 111, D14311, doi:10.1029/2005JD006375, 2006.
Veefkind, J. P., de Haan, J. F., Brinksma, E. J., Kroon, M., and Levelt, P. F.: Total Ozone from the Ozone Monitoring Instrument (OMI) Using the DOAS technique, IEEE T. Geosci. Remote, 44(5), 1239-1244, doi:10.1109/TGRS.2006.871204, 2006.

WMO (World Meteorological Organisation), Scientific Assessment of Ozone Depletion: 2006, Global Ozone Research and Monitoring Project - Report No. 50, 572 pp., Geneva, Switzerland, 2007.

WOUDC: These data were obtained from the World Ozone and Ultraviolet Radiation Data Centre (WOUDC) operated by Environment Canada, Toronto, Ontario, Canada under the auspices of the World Meteorological Organization, available at: http://www.woudc.org/, last access: March 2009. 